В заключении хочется отметить, что интересно было бы рассмотреть механизмы психологической защиты отцов, сравнить их с психологической защитой матерей. А также выявить специфику влияния механизмов психологической защиты отцов на детско-родительские отношения.

\title{
Литература
}

1. Авдеева Н.Н., Хаймовская Н.А. Зависимость типа привязанности ребенка ко взрослому от особенностей их взаимодействия // Психологический журнал. - 1999. Т.20. №1. С.39-48.

2. Базалева Л.А. Безопасность или психологическая опасность в содержании отношений в системе «мать-дитя»// Психология безопасности и психологическая безопасность: проблемы взаимодействия теоретиков и практиков Сборник материалов VII Всероссийского научного семинара, г. Сочи, 9-10 сентября 2016 г. / Министерство образования РФ; Соч. гос. ун-т; Соц.-пед. ф-т СГУ; Под ред. И.Б. Шуванова, В.В. Знакова, З.И. Рябикиной, Г.Ю. Фоменко, В.Ф. Енгалычева, Ю.Э. Макаревской. — Сочи: СГУ, 2016. 168 c. C. $6-13$

3. Базалева Л.А. Личность женщины и материнство //Человек. Искусство. Вселенная. научно-практический журнал. - Центр развития человека, 2015. № 1. C. 114-121.

4. Лунякова Л.Г. О современном уровне жизни семей одиноких матерей // Социологические исследования, - 2001 №8, С. 86-99.

5. Целуйко В.М. Вы и ваши дети. Психология семьи. - Ростов н/Д: «Феникс», 2004. - 448c. (Серия «Психологический практикум»)

\section{О СОВЕРШЕНСТВОВАНИИ ПРОЦЕДУРЫ ПСИХОЛОГИЧЕСКОГО ЭКСПЕРИМЕНТА}

Балин В.Д.

В одном из недавних исследований было показано, что воспроизводимость результатов психологического эксперимента весьма низка. (Science 28 Aug 2015;Vol. 349). Что же является причиной такой низкой воспроизводимости? Ясно, что авторы исследований учитывают и описывают не все условия, в которых производилось психологическое исследование, многие вещи считаются само собой разумеющимися, но на поверку таковыми не являются. Очевидно, что совершенствовать психологическое исследование и эксперимент можно на все его этапах. Мы в данной статье рассмотрим в основном влияние двух факторов психологического исследования на его результаты: 1.Особенности понимания испытуемым инструкции к заданию и сути самой экспериментальной ситуации. 2. Особенности экспериментатора как важного участника экспериментальной ситуации.

1. Понимание инструкции. $\mathrm{B}$ руководствах по экспериментальной психологии проблема понимания испытуемым инструкции обычно упоминается вскользь, как нечто само собой разумеющееся. Если эксперимент проводится в рамках общей психологии, когда используются термины только одного уровня обобщенности, это можно считать допустимым. Однако 
адекватность понимания испытуемым смысла предстоящего задания, как правило, не проверяется и здесь. Поскольку каждый термин и понятие имеют несколько смыслов, то возможно, что экспериментатор имеет в виду один смысл используемого понятия, а испытуемый - другой. Не проверяется и сама ситуация эксперимента: насколько она соответствует цели эксперимента, и не противоречит ли ей?

Данная проблема усложняется, если мы проводим психофизиологический эксперимент. При интерпретации результатов в данном случае соотносятся разноуровневые понятия: общепсихологические (которые, как уже упоминалось, имеют несколько смыслов) и физиологические (и даже физические, если используются электрофизиологические методы исследования), которые, как правило, более однозначные и точные. Во избежание такого расхождения в трактовке исследуемых явлений видится необходимым, в перспективе, разработать многовариантную «таблицу соответствия» психологических и физиологических понятий, где должны быть указаны разные типы соотношений между рассматриваемыми понятиями.

Решение названной проблемы, на первых порах, возможно следующим образом:

I. Работа с испытуемым до эксперимента.

1. Оценка ситуации («фон» экспериментальной ситуации): а) тип ситуации; б) понимания испытуемым ситуации. 2. Подготовка инструкции (экспериментальная «фигура»): а) выявление смысловых уровней инструкции; формулирование рабочей инструкции, б) пилотирование текста инструкции, оценка еe сложности, выбор формы подачи (устная или письменная), экспертная оценка текста инструкции. 3. Измерение степени понимания инструкции испытуемым и степени ее соответствия ситуации с помощью специально разработанной для такого случая формы: а) глубина понимания; б) отчетливость понимания; в) полнота понимания; г) степень включенности инструкции в ситуацию для конкретного испытуемого.

II. Эксперимент, проходящий в соответствии с экспериментальным планом.

III. Работа с испытуемым после эксперимента.

1. Оценка ситуации. Подсчет коэффициента корреляции между пониманием смысла ситуации испытуемым, (определяемого с помощью специального опросного листа), до и после эксперимента. 2. Оценка понимания испытуемым инструкции (определяемого с помощью специального опросника) после эксперимента по отношению к ее пониманию до эксперимента. Подсчет коэффициента корреляции между двумя оценками понимания инструкции. Величина корреляции должна быть не ниже $0,7 \div 0,8$, как это принято считать допустимым в случаях проверки теста на его надежность, валидность, константность и т.п.

При обработке и интерпретации полученного экспериментального материала в качестве дополнительной экспериментальной величины следует брать коэффициенты корреляции между степенью понимания испытуемым ситуации и инструкции до и после эксперимента. Таким образом, будет 
учитываться дополнительный показатель, оказывающий влияние на экспериментальную процедуру и результаты эксперимента.

2. Индивидуальные особенности экспериментатора. На экспериментатора можно посмотреть как на наблюдателя. Проблема наблюдателя в свое время достаточно подробно была разработана в инженерной психологии. Были описаны рабочие характеристики приемника (наблюдателя). В общем плане проблема заключается в поддержании в оптимальном диапазоне показателя рабочих характеристик приемника (РХП), как отношения Сигнал/уровень внутренних шумов. Но что можно считать в нашем случае сигналом, а что - внутренними шумами? В психофизике есть понятие Рабочей характеристики приемника - понятие, заимствованное психофизикой из теории обнаружения сигнала; означает зависимость вероятности правильного положительного ответа от вероятности ложной тревоги. Современная психофизика (в отличие от классической) считает, что увеличение числа ложных тревог приводит к возрастанию числа обнаруженных сигналов и наоборот. Каждой точке критерия принятия решений на оси сенсорных состояний соответствует своя вероятность правильного положительного ответа и ложной тревоги. Перемещая критерий из одной точки в другую, можно получить достаточно полную форму кривой РХП. Рабочая характеристика наблюдателя (PX) - зависимость вероятности попадания от вероятности ложной тревоги.

Каким же образом можно все вышесказанное перевести в практическую плоскость? Во-первых, следует ввести понятие Идеального экспериментатора. Для этого нужно собрать воедино все желательные свойства идеального наблюдателя (экспериментатора) и сформировать паспорт идеального экспериментатора. Во-вторых, нужно сформировать опросный лист, предназначенный для опроса реального экспериментатора в реальных условиях эксперимента. Каждый экспериментатор должен знать свои рабочие характеристики, как экспериментатора. Возможно, что опрос экспериментатора необходимо производить перед началом любого эксперимента, на основании чего решать, может ли в данный момент данный экспериментатор производить данное конкретное исследование. В-третьих, следует ввести понятие: паспорт экспериментатора как реального наблюдателя. Описание экспериментальных процедур должно включать в себя сведения об экспериментаторе и о таком паспорте.

Если продолжать эту линию на более поздние этапы экспериментального исследования, то точно так же следует ввести понятие идеального интерпретатора. Его характеристики также должны быть указаны в паспорте экспериментатора.

Помимо сказанного, на результаты эксперимента влияют и процедуры математической обработки полученного массива чисел. Действительно, вполне справедливо задаться вопросом: «Собственно, свойства чего, какого объекта описывают собранные числа?». Проводя обработку собранного экспериментального материала, существующего в виде совокупности чисел, резонно задать вопрос: «Действительно ли мы изучаем свойства именно 
психологического объекта (существующего для нас в виде набора чисел) с помощью известных статистических процедур, либо мы изучаем свойства самих чисел, которые могут быть и не связанными со свойствами психологического объекта (явления). В руководствах по экспериментальной психологии описана формализованная процедура перехода от области психологических объектов к области чисел с помощью психометрических шкал, созданной в свое время С. Стивенсом. Но там ничего не сказано о формализованной процедуре обратного перехода от области чисел к области психологических объектов. Эту процедуру еще следует разрабатывать.

Таким образом, по мере развития экспериментальной психологии начинают проступать такие проблемы, существование которых еще некоторое время назад невозможно было и допускать. Если психологи хотят повысить точность своих экспериментальных процедур, то эти проблемы надо решать уже сейчас.

\section{ИЗУЧЕНИЕ ЭМОЦИОНАЛЬНЫХ АСПЕКТОВ ВОЛЕВОЙ РЕГУЛЯЦИИ}

\section{Белякова Д.Н.} Научный руководитель: д.псх.н., профессор Мельников В.М.

В настоящее время многие исследователи (О.А. Конопкин, В.И. Чирков, В.А. Иванников) проявляют большой интерес к изучению эмоциональных аспектов волевой регуляции. Такой интерес имеет глубокие корни и во все времена изучался многими психологами.

Согласно теории дифференциальных эмоций психолога Изард К.Э., интерес является доминирующим мотивационным состоянием в повседневной деятельности нормального человека. Зачастую эмоция интереса выступает в комбинации, а иногда в конфликте с одной или несколькими другими эмоциями, и при этом постоянно взаимодействует с перцептивнокогнитивными процессами. Интеракции «интерес - когнитивный процесс» обусловлены аффективно-когнитивными ориентациями, или структурами, характеризующими конструктивную, творческую деятельность здорового индивида. Если все жизненные потребности человека удовлетворены, и он не испытывает отрицательных эмоций, то он способен действовать в соответствии с позитивным мотивационным побуждением, исходящим от аффективнокогнитивных структур, аффективная часть которых представлена эмоцией интереса-возбуждения. Другая положительная эмоция - радость - играет в данном случае второстепенную роль, она поддерживает конструктивное, творческое поведение[1].

Цель исследования - изучение эмоций, которые включены в процесс эмоционально-волевой регуляции.

Объект исследования - эмоция интереса

Предмет исследования - эмоции, возникающие при волевом усилии

Гипотеза исследования - при волевом усилии эмоция интереса является наиболее выраженной. 